Journal of Engineering and Applied Sciences 14 (4): 1162-1168, 2019

ISSN: 1816-949X

(C) Medwell Journals, 2019

\title{
Behavior of Different Materials for Stone Column Construction
}

\author{
Kwa Sally Fahmi, E.S. Kolosov and Mohammed Y. Fattah \\ Peter the Great Saint Petersburg Polytechnic University, Saint Petersburg, Russia
}

\begin{abstract}
There is no doubt that the influence of column material is considered so important to be studied in the performance of the stone column through laboratory experiments on models stone columns which are installed in clayey soil. In current study two reinforcement materials were being studied; stone and sand. In addition, settlement versus load response was determined. The main controlling parameter in the design of the stone column is the grain size of the stone columns material. Under the same loading condition, the weak soil was also analysed and it has been found that the stones are the most effective material. Furthermore, experimental study on the behaviour of a group of four and eight columns was carried out through the finite element analysis with the Software PLAXIS 3D by using 16-noded triangular elements. It has been concluded that the inclusion of piles considerably improve the load-deformation properties of a clay soil. Through studying different pile materials which were used in this study, it has been found that the stones were more effective than sand for single column and group of columns.
\end{abstract}

Key words: Stone column, clay, sand, model test, settlement, numerical analysis

\section{INTRODUCTION}

Before developing the technique of stone columns, considerable attention has been paid to emphasize that the stone columns are utilized as an effective soil improvement which is called vibro flotation and vibro-compaction. The previously mentioned terms are enhanced in order to improve the poor soil layer. Moreover, the construction process consists of forming a cavity by using a vibrator on the ground until reaching the required depth and by lowering and raising the vibrator and backfilling. Typically sand is used as a backfill material for this technique and the technique of stone column is similar to the vibro-compaction method but with a small difference. This difference appears when using the stone columns in that the gravel or crushed stone will be used as a back fill material. Moreover, it can install the stone column in wet or dry methods taking into consideration the conditions of the soil in the dry method also a compressed air can be used in the vibrator and this method is called vibro-displacement stone column (Al-Mohamadi, 1999).

This remarkable method of pouring the gravel or crushed stone column into the holes also known as the bottom feed technique which is directly fed by pipes to the nose of the vibrator. Whereas in the top feed technique, the stone is fed to the ring of the vibrator which is falling by the gravity and the vibrations through the bottom of the ring to the created holes.

Given the fact that in the vibratory probe technique, a heavy vibrator is used which is clamped to the upper end of a long steel probe. The difference between the classical stone column method and the vibratory probe ones is that it induces vertical vibrations and typically the construction process of the method includes the densification of the soil during removal of the probe and the advance of the probe to the required depth. Furthermore, it also can be noticed that a backfill material was used in this method in order to improve the poor soil condition.

Additionally, there is a method called rammed stone column. It is especially, beneficial in the clay-cohesive soils which are constructed by compacted stone columns on the ground through driving the casing to the required depth with high of fall 4-6 $\mathrm{m}$ usually by hammering on a temporary sand or stones plug located at the bottom of the casing.

The rammed stone columns method is constructed by either driving a closed or opened end pipe in the soil or maybe by boring a hole. Stone or sand is filled in the hole in increments by using a heavy, falling weight (Anonymous, 1983).

Literature review: Several researchers have worked on the theoretical part, field and experimental study on the behavior of the stones column such as Gandhi and Ambily. They carried out the detailed experimental study of the behavior of group and single column by different parameters such as shear strength of the clay soil, spacing between the columns and the load conditions subsequently. Ilamparuthi and Malarvizhi studied the settlement versus load response of the stone

Corresponding Author: Kwa Sally Fahmi, Peter the Great Saint Petersburg Polytechnic University, Saint Petersburg, Russia 
columns encased with geogrid in the laboratory. Whereas Andreou et al. (2008) studied the influence of the main parameter that controlled the design of the stone column through the laboratory experiments. Guetif et al. (2003) emphasized the load test on the performed on the clay soil bed reinforced with stone column with different types of encasing materials and various slenderness ratios, the grain size of stone column material. The effect of the drainage conditions, the rate of deformation and the confining pressure of the soil have also been investigated.

The current study aims at determining the effect of different materials of stone column that can be used for construction, also to compare the suitability of different materials. So, this study provides guidelines for choosing the proper material of stone column which can be economic and effective.

\section{MATERIALS AND METHODS}

\section{Experimental investigation}

Clay: A brown clean clay soil was brought from a depth of about $5 \mathrm{~m}$ from the site of a bridge in the sport city within Al-Basrah government. The soil was subjected to routine laboratory tests to determine its properties. Standard tests were performed to determine the physical and chemical properties of the soil, details are given in Table 1 . The soil consists of $4 \%$ sand, $28 \%$ silt and $68 \%$ clay as shown in the grain size distribution (Fig. 1). The tests performed and the relevant standards utilized are listed as follows:

- Water content (ASTMD-2216)

- Atterberg limits (ASTM D-4318)

- $\quad$ Sieve analysis (ASTM D-421)

- $\quad$ Specific gravity (ASTM D-854)

The results show that the soil consists of $6 \%$ sand, $46 \%$ clay and $48 \%$ silt. The soil is classified according to the Unified Soil Classification System USCS as (CL).

The crushed stone and sand: The crushed stone materials were obtained from a private mosaic factory. It was produced as a result of crushing big stones, the crushed stone is of white color with angular shapes. The assessment of mechanical properties of stone columns, the internal friction angle of the constructed and the relative density columns are estimated from the past studies. While the grain size distribution of the stone material is presented in Fig. 2. It has been found that the
Table 1: Physical properties of the clayey soil ${ }^{1}$

\begin{tabular}{lr}
\hline Index property (\%) & Values \\
\hline Natural water content (wc) & 31.1 \\
Liquid Limit (LL) & 37 \\
Plastic Limit (PL) & 27 \\
Shrinkage Limit (SL) & 20 \\
Plasticity Index (PI) & 10 \\
Activity (At) & 0.6 \\
Specific Gravity (Gs) & 2.68 \\
Gravel (larger than 2 mm) & 0 \\
Sand (0.06-2 mm) & 4 \\
Silt (0.005-0.06 mm) & 28 \\
Clay (<0.005 mm) & 68 \\
Classification (USCS) & CL
\end{tabular}

${ }^{1}$ Phy sical properties of the soil in Iraq

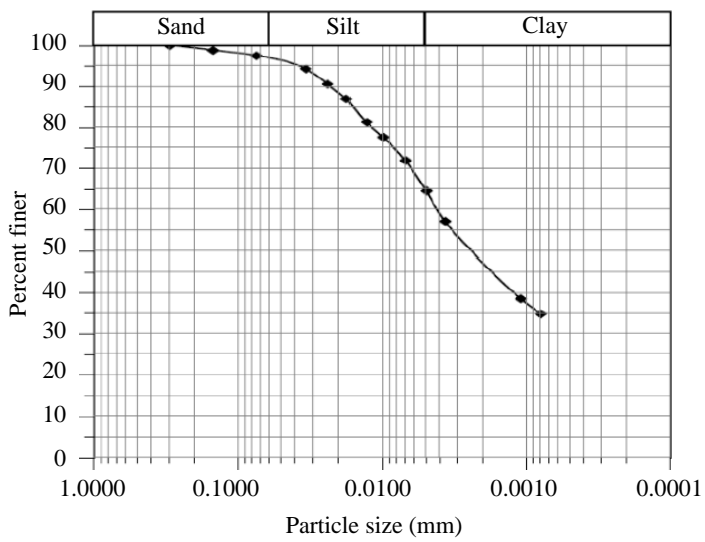

Fig. 1: Grain size distribution of the soil used

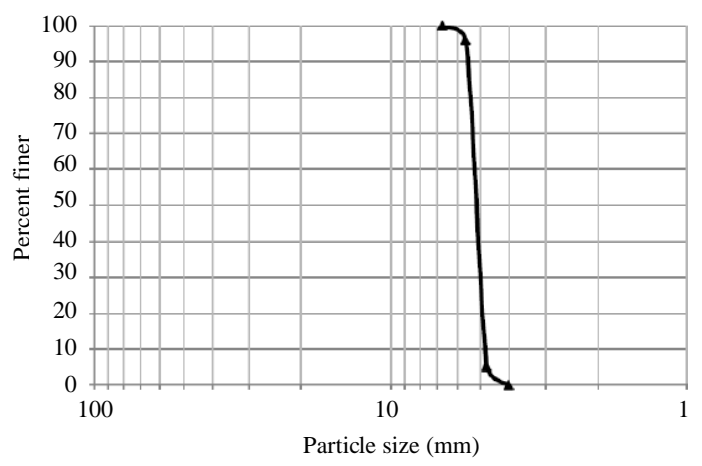

Fig. 2: Grain size distribution of the crushed stone used

engineering properties of the stone columns are estimated based on the sieve analysis as listed in Table 2 while the grain size distribution of the stone material is presented in Fig. 2.

The construction procedure was the same to that followed by Fattah et al. (2016). All the stone columns have a diameter of about $50 \mathrm{~mm}$, Length to Diameter ratio $(\mathrm{L} / \mathrm{D}=6)$ with spacing of 3 times the diameter and area replacement ratio of 0.193 . 


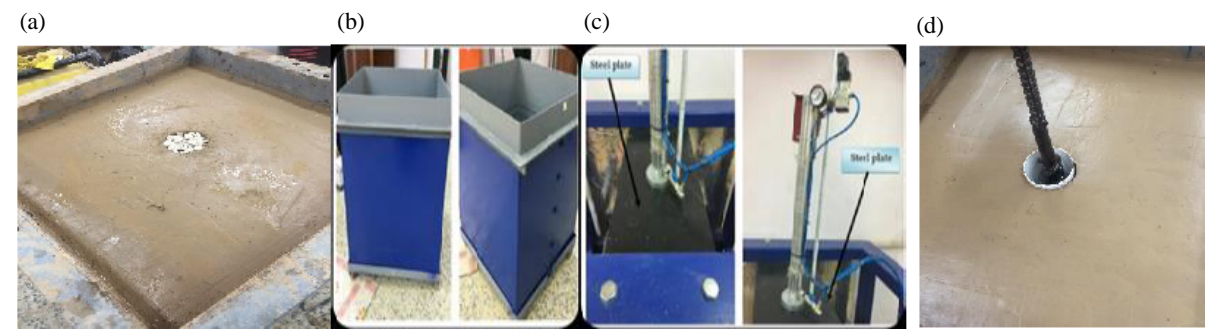

Fig. 3: Experiment investigation

\begin{tabular}{|c|c|c|c|c|c|c|c|c|}
\hline $\begin{array}{l}\text { Index } \\
\text { property }\end{array}$ & $\begin{array}{l}\text { Max. dry unit } \\
\text { weight }\left(\mathrm{kN} / \mathrm{m}^{3}\right)\end{array}$ & $\begin{array}{l}\text { Min. dry unit } \\
\text { weight }\left(\mathrm{kN} / \mathrm{m}^{3}\right) \\
\end{array}$ & $\mathrm{D} 10(\mathrm{~mm})$ & $\mathrm{D} 30(\mathrm{~mm})$ & $\mathrm{D} 60(\mathrm{~mm})$ & $\begin{array}{c}\text { Specific } \\
\text { Gravity (Gs) }\end{array}$ & $\begin{array}{c}\text { Coefficient of } \\
\text { uniformity }(\mathrm{Cu})\end{array}$ & $\begin{array}{l}\text { Coefficient of } \\
\text { curvature }(\mathrm{Cc})\end{array}$ \\
\hline Stone & 17 & 11.56 & 5.20 & 5.1 & 5.22 & 2.64 & 1.04 & 0.956 \\
\hline$\underline{\text { Sand }}$ & 18 & 15 & 0.19 & - & - & 2.60 & 2.50 & 1.080 \\
\hline
\end{tabular}

In order to install the stone columns correctly in their locations, the same frame manufactured by Rahil (2007) was used. Furthermore, the frame consists of two plates connected together by four bolts. The distance between the two plates is $180 \mathrm{~mm}$. Each plate contained eight holes with diameter of about $50 \mathrm{~mm}$ (the same as the diameter of the stone column) and four holes with the same diameter for the second group. The construction of the stone columns started after the preparation of the bed of soil. The depth of each stone column was predetermined corresponding to $\mathrm{L} / \mathrm{D}=6$. A hallow plastic pipe (PVC pipe) with external diameter of $50 \mathrm{~mm}$ was pushed down to the bed to the specific depth with the aid of the frame. To remove the soil inside the PVC pipe, hand anger was used. After that, the soil inside the PVC pipe was removed carefully. The crushed stone and sand were poured into the hole in layers and compacted gently by tamping rod. After pouring all the specific amount of crushed stone, the full depth of the hole was filled with a stone at a dry unit weight of $\left(16 \mathrm{kN} / \mathrm{m}^{3}\right)$ illustrates the process of construction of ordinary stone column. The vertical stress was applied on the specific area at a constant displacement rate $0.048 \mathrm{~mm} / \mathrm{min}$, the dial gauge is used to measure the deformation and a proving ring was used to measure the load.

Numerical analysis of stone columns: To illustrate, the numerical analysis was carried out in current research by using finite element program PLAXIS 3D to compare the behavior of different materials that have been used in experimental investigation. Thus, the analysis was done by using Mohr-Coulomb failure criterion for the stone column and surrounding soil. A drained analysis was adopted for clay soil and assumed for all materials. The 15 nodded triangular elements were used for meshing. Moreover, the boundary condition is used to present the behavior of stone, sand and surrounding soil with radial
Table 3: Parameters of materials used in the analy sis

\begin{tabular}{lll}
\hline Properties & Soft clay & Stone column \\
\hline Unsaturated unit weight $\left(\gamma\right.$ unsat) $\left(\mathrm{kN} / \mathrm{m}^{3}\right)$ & 13.8 & 15 \\
Saturated unit weight $(\gamma \mathrm{sat})\left(\mathrm{kN} / \mathrm{m}^{3}\right)$ & 18.3 & 16.6 \\
Material model & Hardening soil & Mohr-Coulomb \\
Drainage type & Undrained $(B)$ & Draind \\
$\mathrm{E}(\mathrm{kPa})$ & - & 30000 \\
E50 ref $(\mathrm{kPa})$ & 600 & - \\
Eoed ref $(\mathrm{kPa})$ & 1425 & - \\
Eur ref $(\mathrm{kPa})$ & 1800 & - \\
Power $(\mathrm{m})$ & 1 & - \\
Cohesion $(\mathrm{Cu})(\mathrm{kPa})$ & 10 & 1 \\
Friction angle $(\emptyset \mathrm{u})(\mathrm{deg})$ & - & 41.5 \\
\hline
\end{tabular}

deformation was restricted but allowed for settlement. The following figure present the typical deformation mesh for single and group columns with different material. The material properties are listed in Table 3.

\section{RESULTS AND DISCUSSION}

Generally, it has been found that the load-settlement curves are non-linear, typically diagrams of different load-displacement were drawn for all test conditions. Load- deformation characteristics of clay treated with single stone column, loading test was carried out on clay soil and load-deformation curves were plotted for clay treated with columns made of different materials and for untreated clay (Ahmed, 1998), it was found that stones were most effective in comparison with the sand material. Figure 4 shown the arrangement of stone columns with different spacing between them. Figure $4 a, b$ shown the Finite-element discretization for clay soil reinforced with single and group stone columns (Fig. 5).

Load deformation characteristics of clay treated with column groups: Even though a conclusion may review the main results or contributions of the study do not duplicate the abstract or the introduction. For a conclusion, you might elaborate on the importance of the work or suggest the potential applications and extensions. 
(a)

(b)
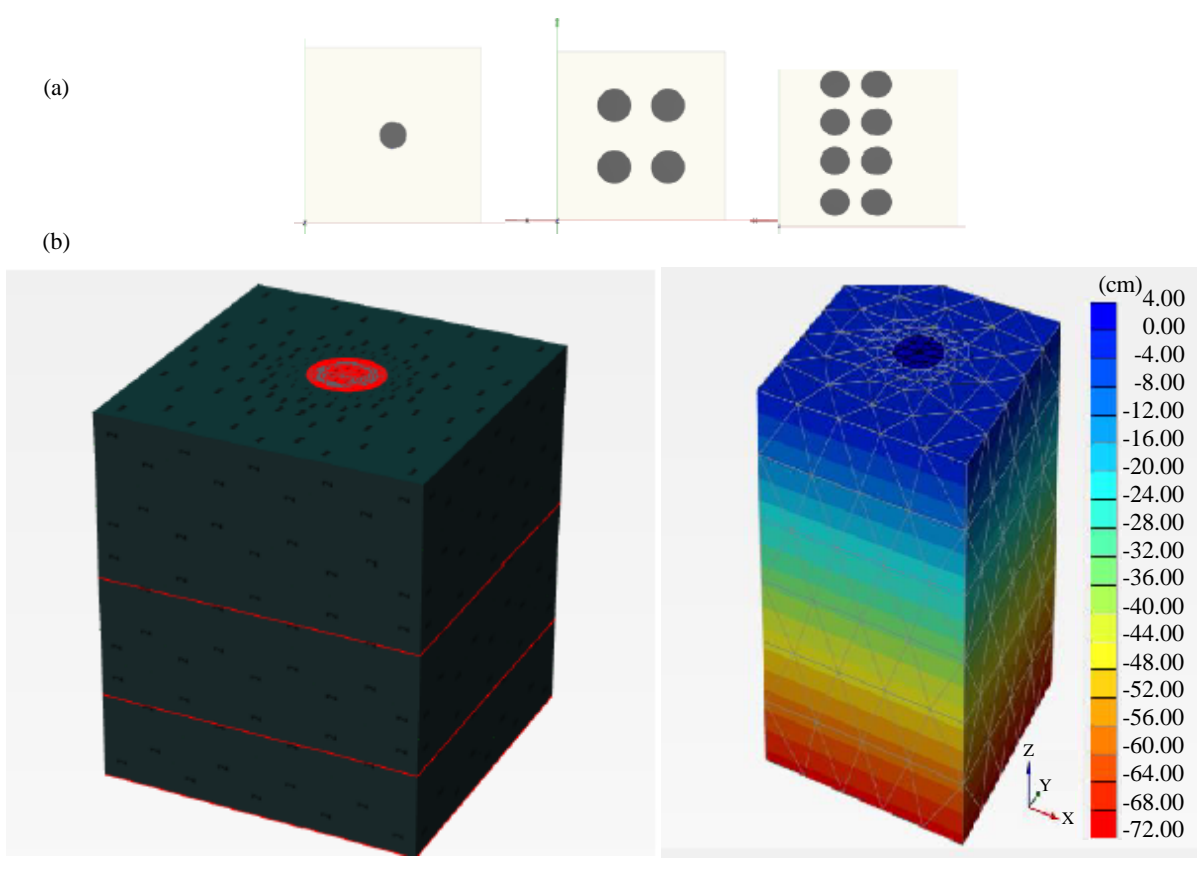

(c)

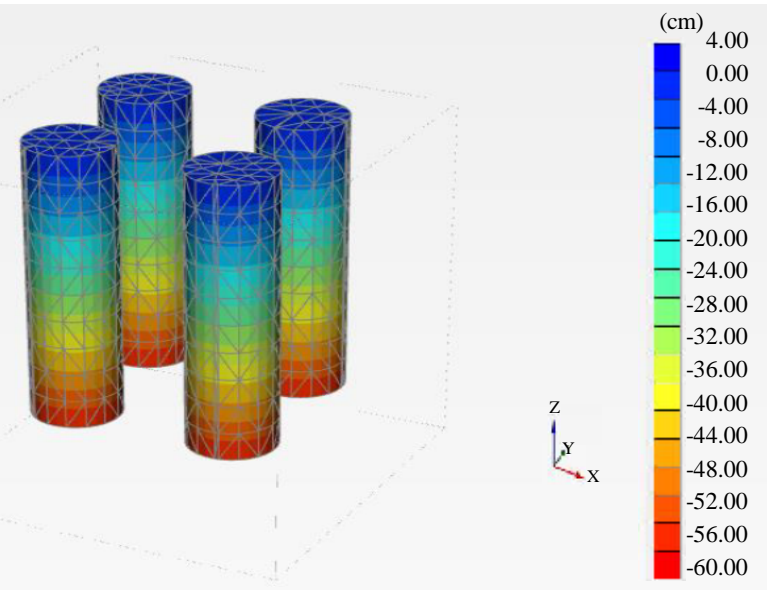

Fig. 4: a) Arrangement of single, eight and four columns in a group; b) Finite-element discretization for clay soil reinforced with single column, typical deformed mesh and c) Finite-element discretization for clay soil reinforced with group column, typical deformed mesh

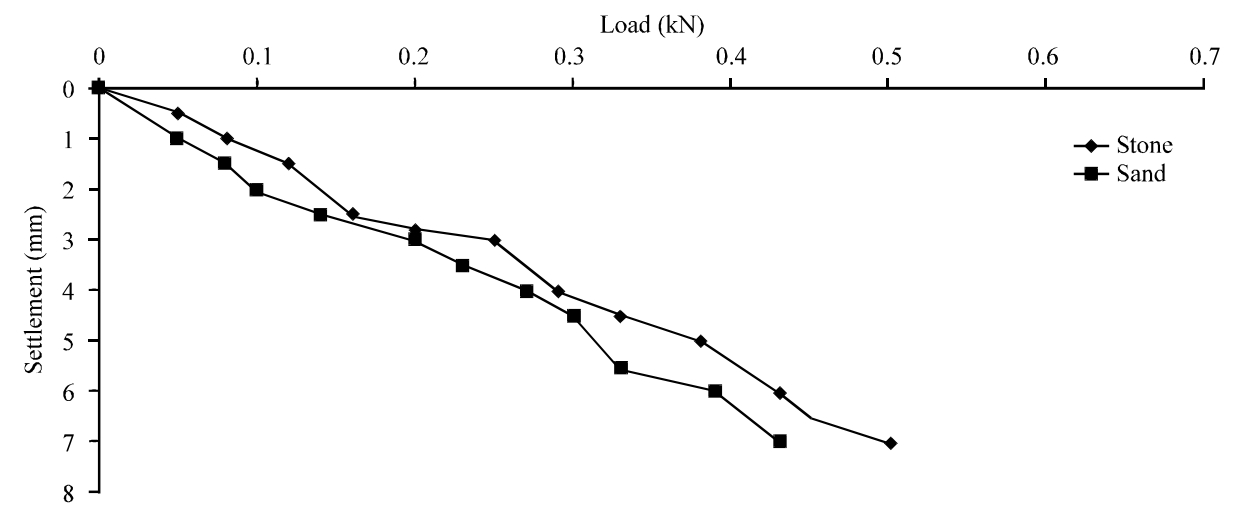

Fig. 5: Load -settlement curves for clayey soil treated with single stone column 


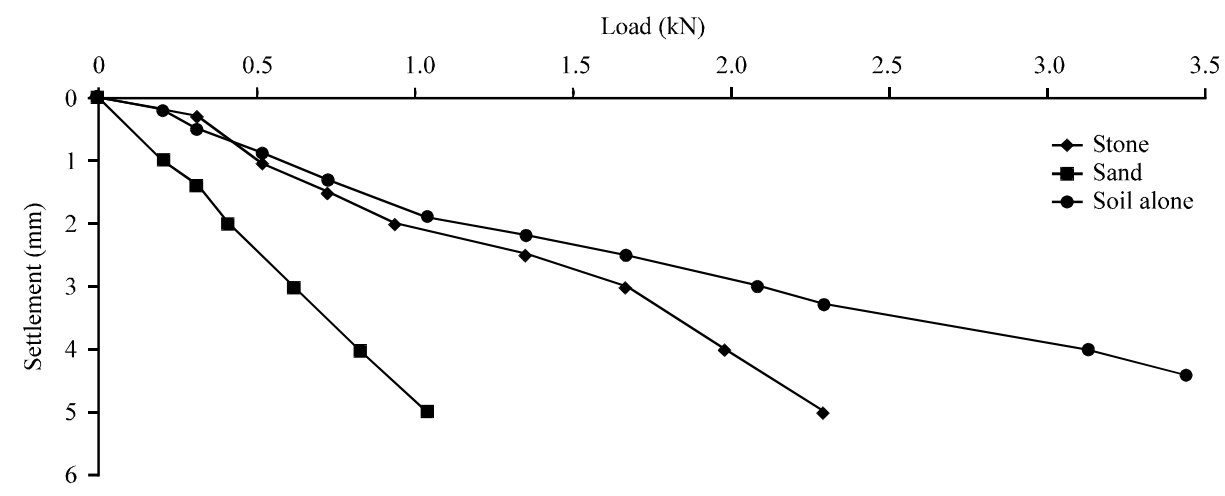

Fig. 6: Load-settlement curves for clay treated with group of 8 stone columns, $\mathrm{s}=3 \mathrm{~d}$

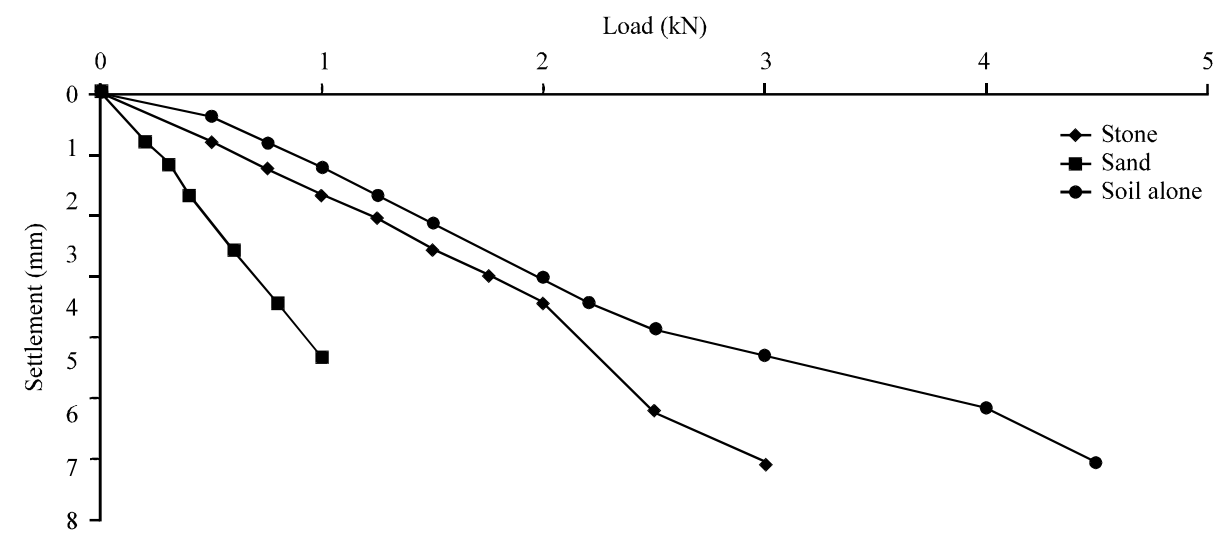

Fig. 7: Load-settlement curves for clay treated with group of 8 stone columns, $\mathrm{s}=2.5 \mathrm{~d}$

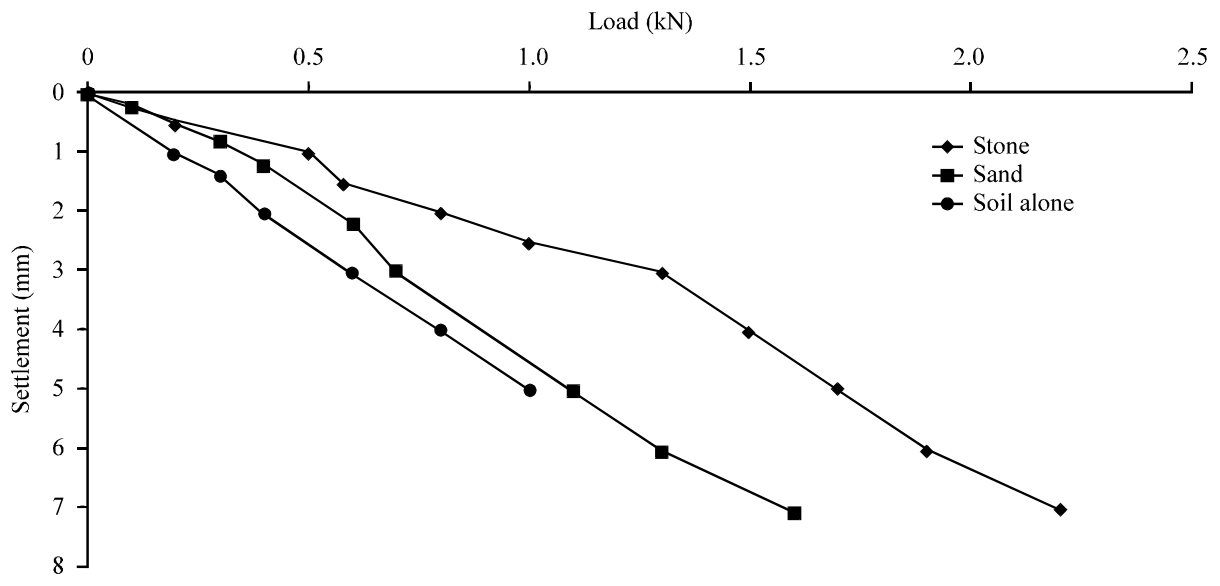

Fig. 8: Load-settlement curves for clay treated with group of 4 stone columns, $s=3 d$

From the outcome of our investigation it has been found that the load-deformation curves of 8 column group and 4 column group showed a similar direction as shown in Fig $4 \mathrm{a}, \mathrm{b}$ and 5 . It has been demonstrated that the load-deformation improved by using a group of 4 columns and much using the group of 8 columns.
The existed test was carried for 2 spacing $2.5 \mathrm{~d}$ and 3 d. From these tests, it has been found that the load capacity increased with decreased of spacing between columns (Fig. 6-12).

Comparison of experiment investigation and FEM analysis: For the resulting plot, Fig. 8 shows the axial 


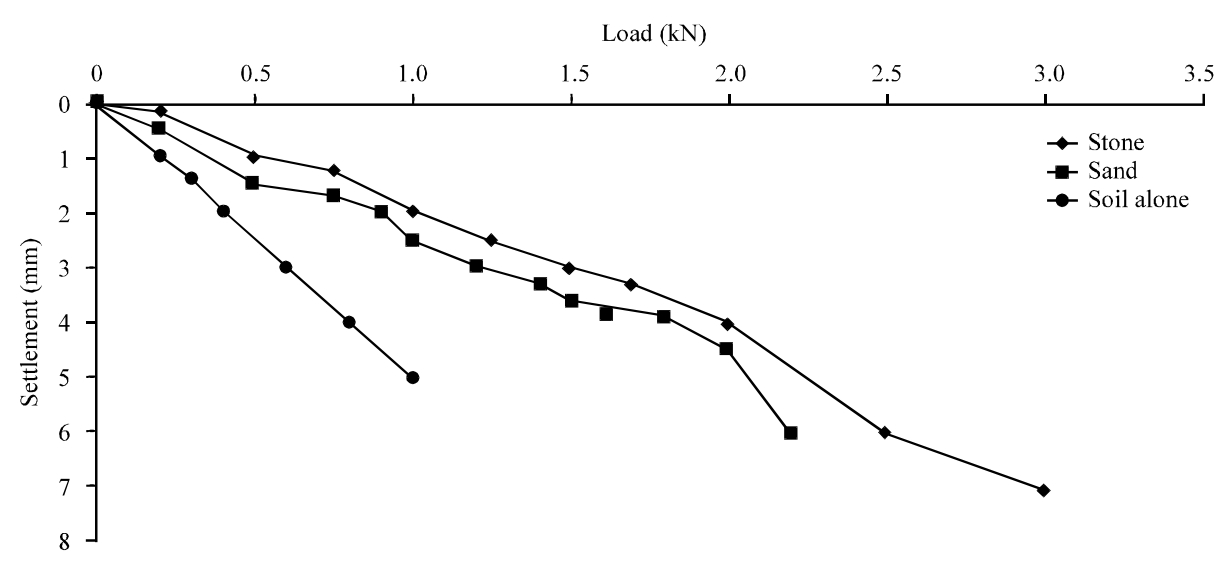

Fig. 9: Load-settlement curves for clay treated with group of 4 stone columns, $\mathrm{s}=2.5 \mathrm{~d}$

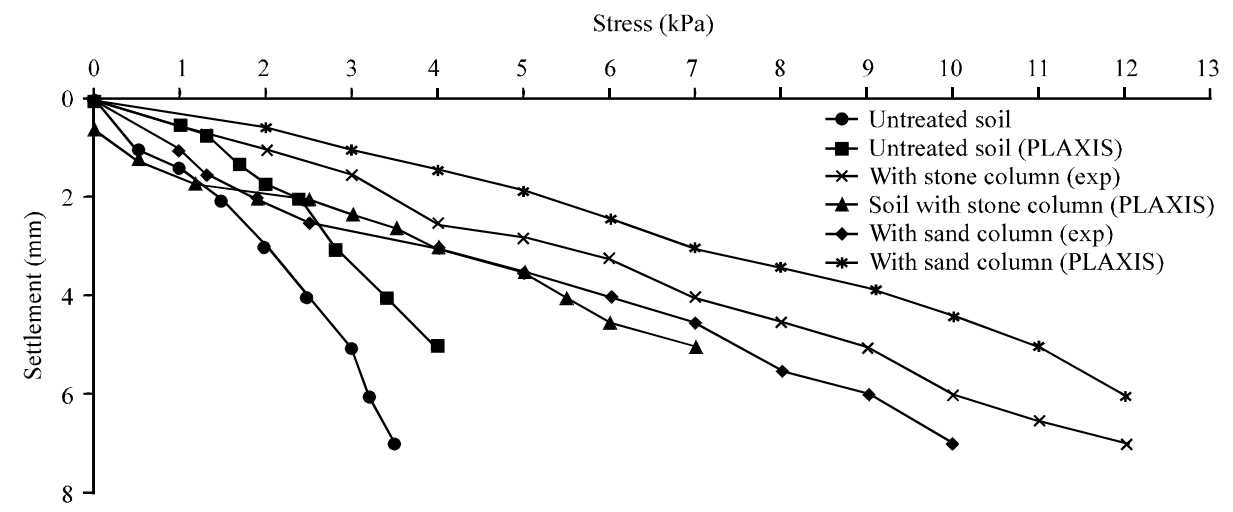

Fig. 10: Comparison of stress settlement relation for clay treated with single columns

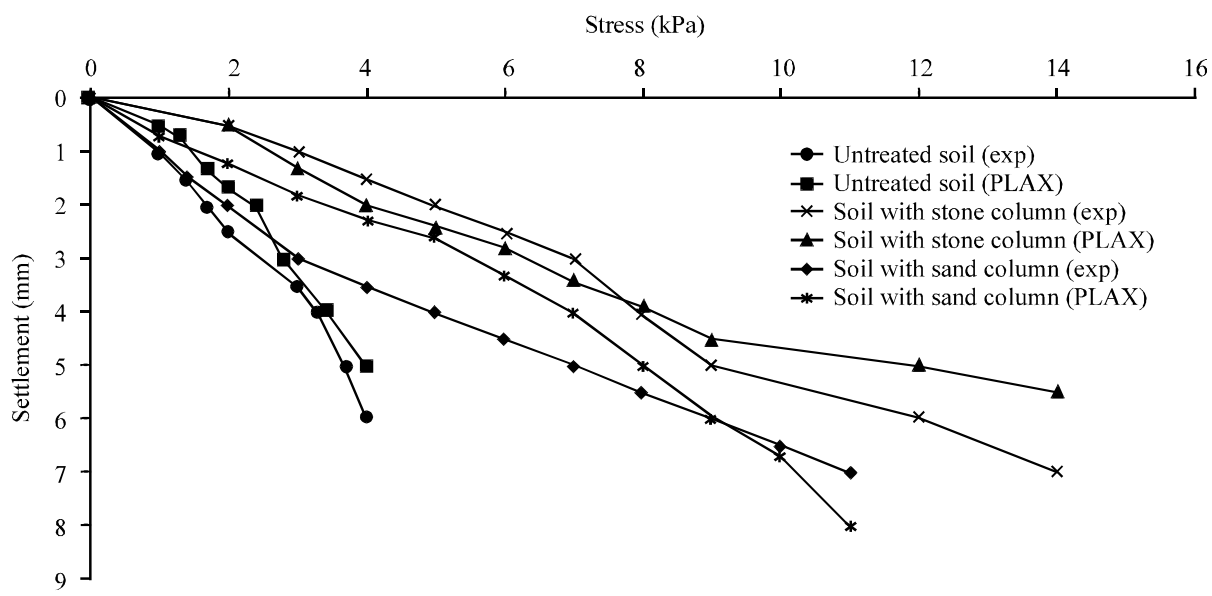

Fig. 11: Comparison of stress-settlement relation for clay treated with group of 8 columns ( $s=3 \mathrm{~d}$ )

stress versus settlement for improved and unimproved soil based on model tests and finite-element analysis for single column. As shown in Fig. 9, the stress versus settlement relation for a group of eight based on the model tests and finite-element analysis. Figure 10 indicates the stress versus settlement relation for a group of four based on the model tests and finite-element analysis. 


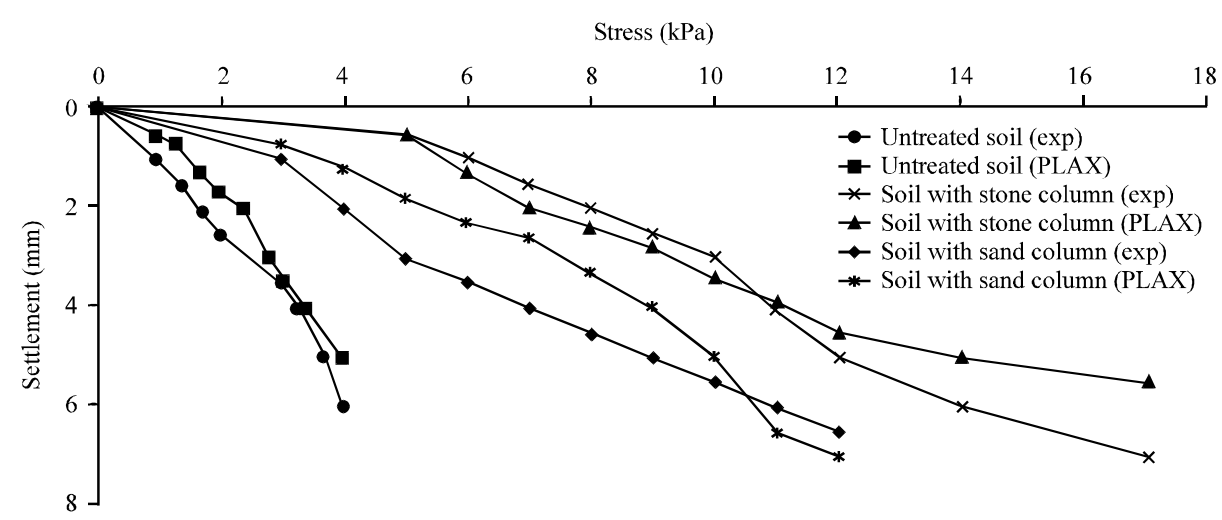

Fig. 12: Comparison of stress-settlement relations for clay treated with group of 8 columns ( $s=2.5 \mathrm{~d}$ )

\section{CONCLUSION}

From the outcome of our investigation it is possible to conclude that: the inclusion of piles considerably improve the load-deformation properties of a clay soil. From the study of different pile materials used, the stones were found to be most effective than sand for single column and group of columns. By using finite element method with Software PLAXIS 3D, close results to the experimental results were obtained. The load capacity increased with decreased of spacing between columns.

\section{REFERENCES}

Ahmed, A.A., 1998. Performance of stone columns in soft soils. Ph.D Thesis, Department of Civil Engineering, University of Baghdad, Baghdad, Iraq.

Al-Mohamadi, F.H., 1999. Substitute of pile by using stone column. MSc Thesis, Department of Civil Engineering, University of Baghdad, Baghdad, Iraq.

Andreou, P., W. Frikha, R. Frank, J. Canou and V. Papadopoulos et al., 2008. Experimental study on sand and gravel columns in clay. Proc. Inst. Civil Eng. Ground Improv., 161: 189-198.
Anonymous, 1983. Design and construction of stone columns, Volume 1. FHWA-RD-83-026, Ground Improvement Publications-Federal Highway Administration, Washington, D.C., USA. https://www.fhwa.dot.gov/engineering/geotech/libr ary_arc.cfm?pub_number $=28$

Fattah, M.Y., B.S. Zabar and H.A. Hassan, 2016. Experimental analysis of embankment on ordinary and encased stone columns. Intl. J. Geomech., 16: 04015102-04015102.

Guetif, Z., M. Bouassida and J.M. Debats, 2003. Parametric study of the improvement due to vibro-compacted columns installation in soft soils. Proceedings 13th Regional African Conference on Soil Mechanics and Geotechnical Engineering, December 8-11, 2003, Morocco Publication House, Marrakech, Morocco, pp: 463-466.

Rahil, F.H., 2007. Improvement of soft clay underneath a railway track model using stone columns technique. Ph.D Thesis, University of Technology, Iraq, Baghdad, Iraq. 